\title{
Reflexóes sobre cidadania e os entraves para a participação popular no SUS
}

| 1 Jean Camargo Longhi, ${ }^{2}$ Giselle Alice Martins Canton |

Resumo: Este trabalho apresenta as contradições do conceito de cidadania encontradas em pesquisas realizadas junto a usuários de uma unidade de saúde da zona leste de São Paulo e os consequentes entraves para a participação popular no SUS. A coleta dos dados foi organizada em dois encontros, sendo abordado o conceito de cidadania e participação popular com oito sujeitos não pertencentes ao conselho gestor da unidade. Utilizou-se a técnica de grupo focal. Como resultado, verificou-se uma imprecisão de significados aplicados ao conceito de cidadania. Os sujeitos da pesquisa apontaram uma série de limites para a execução deste conceito, como a legislação do próprio Estado, a repressão sofrida pelos indivíduos, a descrença na democracia representativa e no voto como práticas de cidadania e o questionamento da igualdade de direitos em nossa sociedade; e a participação popular como forma de movimento coletivo em busca de soluções aos problemas da comunidade. Portanto, a participação popular dentro dos espaços institucionais do SUS com esta concepção de cidadania pode levar os usuários à não resolutividade de suas demandas junto ao Estado nos conselhos gestores. Somente com outras formas de pressão e mobilização nãoinstitucionais, podemos ter uma participação popular mais efetiva e resolutiva, atendendo aos anseios da população e dos militantes em saúde que primam por uma saúde pública e de qualidade.

> Palavras-chave: cidadania, participação popular em saúde, SUS.

\footnotetext{
1 Fonoaudiólogo; residente em Saúde da Família, Faculdade Santa Marcelina. Endereço eletrônico: camargo.longhi@ yahoo.com.br

${ }^{2}$ Assistente social; doutora em Serviço Social pela PUCSP; preceptora acadêmica do Programa de Residência Multiprofissional em Saúde da Família, Faculdade Santa Marcelina. Endereço eletrônico: gicanton@terra.com.br
}

Recebido em: 22/10/2009. Aprovado em: 14/06/2010. 
Este estudo foi alavancado após participação periódica nas reuniões do conselho gestor local de uma unidade de saúde da zona leste de São Paulo onde estava inserida uma equipe de cinco residentes das áreas de fonoaudiologia, nutrição, psicologia, fisioterapia e enfermagem do Programa de Residência Multiprofissional em Saúde da Família. Após um ano de acompanhamento das reuniōes, percebeu-se uma desarticulação entre os conselheiros de todos os segmentos, assim como falhas na divulgação das datas e horários das reuniões, baixa representatividade dos segmentos (composto legalmente por 50\% de usuários, 25\% de representantes dos trabalhadores da saúde e $25 \%$ das vagas para o gestor e prestadores de serviços ao SUS) e desconhecimento dos usuários sobre a existência desse espaço, o que vem comprometendo sua efetividade e resolutividade.

Esse cenário levou a refletir sobre a concepção do termo "cidadania", tão presente desde sua legitimação com a Constituição Federativa de 1988 (BRASIL, 1988) conhecida como "Constituição Cidadã", passando pelas leis de saúde ${ }^{\circ} \mathrm{S}$ 8.080 e 8.142 , que estabelecem as instâncias de participação popular na saúde; e os entraves que inviabilizam a participação popular, visto que esta é um dos pilares do Sistema Único de Saúde (SUS).

A participação da comunidade constitui uma das diretrizes do SUS, sendo contemplada no artigo 198 da Constituição Federal de 1988: “... Esta por sua vez é uma forma de controle social, que possibilita à população por meio de seus representantes definir, acompanhar a execução e fiscalizar as políticas de saúde...”. (BRASIL, 2001).

No período de distensão política brasileira, pós-ditadura militar, o processo de alargamento da democracia se expressa na criação de espaços públicos e na crescente participação da sociedade civil nos processos de discussão e de tomada de decisão relacionados com as questôes de políticas públicas (TEIXEIRA et al., 2002). O marco formal desse processo é a Constituição de 1988, que consagrou o princípio de participação da sociedade civil. As principais forças envolvidas nesse processo compartilham um projeto democratizante e participativo, construído desde os anos 1980 ao redor da expansão da cidadania e do aprofundamento da democracia. Assim, o significado político crucial da participação é radicalmente redefinido e reduzido à gestão. A ênfase gerencialista e empreendedorista transita da área da administração privada para o âmbito da gestão estatal, como relata Tatagiba (2003), com todas as implicações despolitizadoras delas decorrentes. 
O Estado e os setores da sociedade civil comprometidos com o projeto participativo democratizante substituem o confronto aberto da década anterior, período de ditadura militar, por uma aposta na possibilidade de uma atuação conjunta com o Estado através de espaços institucionalizados de participação popular. A chamada "inserção institucional" dos movimentos sociais é evidência dessa inflexão. $\mathrm{O}$ confronto e o antagonismo que tinham marcado profundamente a relação entre o Estado e a sociedade civil nas décadas anteriores cederam lugar a uma aposta na possibilidade da sua ação conjunta para o aprofundamento democrático.

A Constituição de 1988 concebe a noção de Estado democrático de direito. Este passa a garantir, além da proteção das liberdades individuais, a participação destes na formulação e monitoramento de suas políticas públicas. Segundo essa compreensão, Chauí (2002) afirma que o Estado procura instituir os diversos interesses e necessidades particulares existentes na sociedade em direitos universais reconhecidos formalmente. Os indivíduos e grupos organizam-se em associações, movimentos sociais, sindicatos e partidos, constituindo um contrapoder que limita o poder do Estado. A participação popular na saúde deve ser entendida como a "partilha efetiva do poder" entre Estado e sociedade civil, segundo Dagnino (2002), por meio do exercício da deliberação no interior dos espaços públicos e em outros espaços de luta não-institucionais que a sociedade entenda como pertinente para mudanças na estrutura social de um país, percebendo que somente dessa forma pode mudar as condições de saúde de uma população.

$\mathrm{Na}$ defesa e construção desses direitos incluídos nas leis de saúde, Bosi e Afonso (1998) fazem duas colocações essenciais: a elaboração de uma consciência sanitária definida como o entendimento de que a saúde é um direito; e a participação popular como um mecanismo fundamental para esta construção. Nesse sentido, Carvalho (1995) e Sousa (2003) apontam que esta participação é construída diretamente pela ação de diversos segmentos sociais, tendo como instrumento processos que envolvem a organização, mobilização, denúncia e pressão no sentido de luta e contestação.

É importante apontar que o conceito de cidadania vem sendo modificado ao longo da história. Desde sua criação na Grécia antiga até os dias atuais, utiliza-se o termo em benefício de determinados setores das sociedades. Com isso tornase importante compreender a construção histórica desse conceito correntemente 
usado na atualidade. A origem do termo vem da Grécia antiga, onde tinha o significado daquele "pertencente à Pólis". Na constituição de Atenas, o cidadão traz como direito ou prerrogativa a participação nas práticas deliberativas ou judiciárias da comunidade a que pertence. Segundo Welmowicki (2004), a definição de cidadania passa por um exame seletivo, já que existe a separação entre os cidadãos e os não-cidadãos (escravos e/ou estrangeiros).

Mais tarde, no final do século XVII, os teóricos da burguesia inglesa, a primeira que ascendeu ao poder, formularam com muita clareza os conceitos de liberdade e de indivíduo para desenhar os alicerces da sociedade burguesa em construção. Esses tinham como base a primazia do indivíduo, do qual derivou sua visão do individualismo liberal, identificando como direito natural o direito à propriedade (WELMOWICKI, 2004).

Essa concepção, que tinha em sua raiz a luta contra os privilégios feudais e a defesa da propriedade burguesa contra os ataques arbitrários dos reis e da nobreza (significava o fim das instituições de "sangue" e títulos), também delimitava os parâmetros de cidadania para a nova sociedade: liberdade é, em última palavra, o direito à propriedade. $\mathrm{O}$ voto censitário, ou seja, voto somente daqueles que têm determinado rendimento ou propriedade, assegurava a preservação da propriedade privada e marcou a fase de ascensão da burguesia.

Nesse período existiu uma igualdade jurídica, segundo a qual perante a lei todos eram iguais, sendo vedado o direito de "impor a sociedade" algo que não estivesse previsto em leis ou que fosse contrário ao decidido pelos juízes. Para Welmowicki (2004), a cidadania significava garantir a liberdade individual e, em particular, a "liberdade" do trabalhador como indivíduo dono de si mesmo pronto para ser livremente explorado.

A versão moderna de cidadania teve início no mundo pós-Segunda Guerra Mundial. Saído da guerra como potência dominante, os Estados Unidos da América teve de pensar numa política que permitisse canalizar o descontentamento social e desse respiro para que o capitalismo voltasse a se estabilizar na Europa. Surge assim o Plano Marshall, uma política de financiamento dos novos governos europeus para que pudessem reconstruir suas economias e implantar reformas sociais do assim chamado Welfare State. Este significava estender os direitos sociais aos setores operários atingidos pelas consequências da Segunda Guerra como melhoria dos serviços públicos e a intervenção estatal na economia 
para impulsionar sua recuperação. Marshall retoma o conceito de cidadania como um status de todos os que pertencem a uma determinada comunidade, que significaria uma igualdade como tal.

A cidadania moderna, conceito fundado sobre a ideia de humanidade, enfrentou muitas dificuldades de aplicação, dentre elas o tamanho das repúblicas modernas, o que impede o exercício direto do poder pelo cidadão, sendo necessária a escolha de seus representantes (VIEIRA, 2005). A disseminação dessa concepção de cidadania foi expressiva, e ela orientou não só as práticas políticas de movimentos sociais de vários tipos, mas também mudanças institucionais, como as incluídas na Constituição brasileira de 1988, que traz no seu artigo 196 a seguinte definição de saúde: "A saúde é direito de todos e dever do Estado, garantido mediante políticas sociais e econômicas que visem à redução do risco de doença e de outros agravos e ao acesso universal igualitário às açōes e serviços para sua promoção, proteção e recuperação" (BRASIL, 1988).

Essa concepção de cidadania reivindica o acesso, inclusão, participação e pertencimento a um sistema político já dado. O reconhecimento dos direitos de cidadania aponta para transformaçōes radicais em nossa sociedade e em sua estrutura de relações de poder. Tornar-se cidadão passa a significar a integração individual ao mercado, como consumidor e como produtor. Este parece ser o princípio subjacente a um enorme número de programas para ajudar as pessoas a "adquirir cidadania", isto é, aprender como iniciar microempresas, tornar-se qualificado para os poucos empregos ainda disponíveis, por exemplo. Num contexto onde o Estado se isenta progressivamente de seu papel de garantidor de direitos, o mercado é oferecido como uma instância substituta para a cidadania (DAGNINO, 2004). Portanto, a noção de cidadania se opõe à de identidade de classe, uma vez que existem propostas e interesses distintos e opostos por trás de cada uma delas. Cidadania passa a ser uma categoria abstrata, desligada da práxis real e dos conflitos inerentes à sociedade capitalista.

O Estado, órgão representante da classe social dominante, através de suas instituições (escola, igreja, parlamento, partidos políticos, justiça, entre outros) legitima ideologias da classe dominante e as dissemina entre a população, tornando-se um entrave para o desenvolvimento desta e o avanço da humanidade. Essas ideologias não passam de uma estratégia da classe dominante na negociação das desigualdades, de modo a reduzir as tensões sociais e para se manter no poder, 
seguir na linha da conciliação de classes e continuar explorando e oprimindo as demais classes e setores. Entendemos o conceito de cidadania como uma dessas ideologias que vêm desde nossa Constituição Federativa e seguem ecoando nas demais leis de saúde e sobre a consciência da classe trabalhadora. Esta "ideologia ou falsa consciência”, como colocam Marx e Engels (2006), passa a prestar serviço ao Estado representante da classe dominante como forma de evitar tensões sociais e como manutenção da ordem.

Mesmo compreendendo as diferenças radicais entre os conceitos de "cidadania" e "classe", e ainda tecendo críticas às implicações ideológicas e sociais do conceito de cidadão, optaremos, neste trabalho, pelo uso do conceito "cidadania". Tal escolha se justifica pelo uso desta nomeação entre o setor de usuários (classe trabalhadora). Nesse ínterim, através do conceito de cidadania, poderemos analisar os principais conceitos de atuação do usuário como sujeito político em saúde, apontando as características da participação popular defendidas pelos entrevistados. Ao falar da participação popular, os usuários defenderam um conceito de atuação, que na sociedade capitalista é reduzido ao de cidadania assim, analisando as narrativas, teremos acesso à ideologia dominante.

Ouvir a representação formulada sobre cidadania e participação popular de usuários, sujeitos desta pesquisa, vem ao encontro das preposiçôes de sujeito proposta por Bakhtin (1992), o qual coloca que o sujeito se constitui na e através da interação e reproduz na sua fala e na sua prática seu contexto imediato e social. Por meio de suas falas, os sujeitos expressarão sua visão de atuação na sociedade, revelarão a ideologia presente nos seus discursos e na sua relação com a saúde e apontarão implicitamente as contradições entre sua situação de classe trabalhadora e a defesa do termo "cidadania" em contraposição ao de "classe".

\section{Percurso metodológico}

Neste trabalho foi utilizada abordagem de pesquisa qualitativa do tipo exploratória. Qualitativa, segundo Martinelli (1999), reconhece a singularidade do sujeito, de sua experiência social, bem como de seu modo de vida; e exploratória, já que permite ao investigador aumentar seu conhecimento sobre o fenômeno, aprofundando seus estudos nos limites de uma realidade específica (TRIVIÑOS, 1987). 
Utilizou-se a técnica de grupo focal, proposta por Gatti (2005), a qual permite compreender processos de construção da realidade por determinados grupos sociais, compreender práticas cotidianas, ações e reações a fatos e eventos, comportamentos e atitudes - ou seja, propicia um espaço para que possa haver uma reflexão sobre determinado assunto construída coletivamente. Foram realizadas duas sessões, das quais participaram os mesmos sujeitos, utilizando a técnica de grupo focal, com duração média de duas horas, a primeira abordando o conceito de cidadania e a segunda, participação popular.

Os sujeitos da pesquisa foram oito usuários de uma unidade básica de Saúde da Família da zona leste de São Paulo que, após contato com agentes comunitários de saúde, foram indicados por possuírem alguma história de participação comunitária em associações de moradores de bairro, pastoral da criança ou trabalhos comunitários na igreja. Optou-se por indivíduos não participantes de espaços do controle social da saúde, para que não tivéssemos falas viciadas carregadas de termos administrativos e pudéssemos obter uma percepção mais apurada do entendimento da população usuária do SUS sobre os temas. Neste, buscaremos compreender, por meio das narrativas dos sujeitos participantes, o entendimento acerca do significado que atribuem ao conceito de participação popular e cidadania. Este trabalho foi aprovado pelo Comitê de Ética e Pesquisa da Secretaria Municipal de Saúde de São Paulo, e todos os participantes assinaram o termo de consentimento livre e esclarecido.

Para incentivar as reflexôes sobre os temas, foram propostas algumas dinâmicas. Nesse sentido, esperava-se que cada participante pudesse ser mobilizado para refletir sobre os conceitos de cidadania e participação popular e, a partir de então, fosse formado um ambiente propício para um maior aprofundamento e criticidade na discussão sobre as representações advindas do grupo.

Para análise dos dados, utilizaram-se as sugestôes propostas por Gatti (2005). Assim, após as transcrições das narrativas oriundas dos encontros do grupo focal, foram elaboradas categorias a partir das falas, destacando-se o que foi relevante para o grupo, configurando tendências - ou seja, foram agrupadas as opiniões, comparando-se e confrontando posições, extraindo significados das falas ou de outras expressões registradas, analisando-se a vinculação desses grupamentos com as variáveis contempladas na composição do grupo. Após, foram realizados a composição e o confronto das representações com as teorizaçôes. 
Resultados e análise

A análise do material obtido nos grupos focais levantou um grande volume de informações que, após sucessivas leituras e classificaçōes, foram organizadas em torno de três grandes temas, por meio dos quais se procurou apreender nosso objeto: o conceito de cidadania, os limites desta cidadania e o conceito de participação popular.

\section{O conceito de cidadania}

Ao relatarem experiências pessoais de exercício de cidadania, os sujeitos evidenciaram diversos entendimentos sobre o tema. No discurso de alguns participantes, encontramos falas que apontavam no sentido de a cidadania ser um "ato de solidariedade" ou de "amor ao próximo", com uma visão assistencialista de promover o bem-estar do outro como um ato de caridade.

P2: “[...] dividir com a pessoa independente de conhecê-la, de saber quem é".

P4: "Ele entra doente no hospital, a gente vai lá fazer um trabalho de visita, conversa, levanta um pouco o animo dele né, porque ele necessita, ele é humano, meu irmão também e eu me sinto bem fazendo isso, pra mim é uma ação de cidadania”.

P5: "Ação de cidadania é você se doar, né?"

P7: "Caminhar e ser cidadão a partir da nossa consciência de que o amor está acima de qualquer coisa".

$\mathrm{Na}$ literatura, o conceito de cidadania é utilizado por diversos autores com significados nem sempre coincidentes e que prestam múltiplas interpretações. Os relatos dos sujeitos nos grupos vão ao encontro do exposto por Dagnino (2004), que é através do entendimento de cidadania restrito à responsabilidade moral privada que a sociedade passa a se engajar no trabalho voluntário e filantrópico. A autora complementa que a cidadania é vista como mera caridade, reduzida à solidariedade para com os pobres.

Porém, em outras falas empregaram cidadania como concepção de buscar e exercer direitos e cumprir deveres dentro de um Estado provedor, que entende todos os indivíduos como iguais e sobre sua tutela.

P4: "Eu acho que a gente ser cidadão é cobrar nossos direitos, temos direitos e isto é cidadania ser cidadão de verdade, viver [...] cobrar o que é direito de cada um e então é cidadania, ser cidadão". 
P1: "também não é só pensar em si próprio, é pensar no próximo também, todos tem direitos iguais, isso é cidadania aqui”.

P8: "Lutar pelos direitos que abrange tudo isso que foi falado aqui, ser cidadão tem direitos e deveres".

P4: "É direito nosso como cidadão votar e reivindicar nossos direitos também".

Nesse sentido, Dagnino (2007) trabalha a noção de cidadania como direito a ter direitos, em que o cidadão não se limita a provisões legais, definidos previamente, mas sim a invenção/criação de novos direitos que surgem de lutas específicas e de suas práticas concretas, estando de acordo com o encontrado nos relatos dos participantes.

Outra parcela dos usuários trouxe experiências de exercício da cidadania relacionadas à saúde, essas se efetuaram, também, na busca e execução de direitos da população.

P4: "Eu só tava pedindo pra que mandasse uma multa mesmo pro dono do terreno por causa do lixo [...] fui atendida mal mesmo na prefeitura, então o meu direito de cidadã não foi exercido, então tem muitas pessoas a partir daí, eu acredito, muitas pessoas se tornam umas alienadas e não procuram nem mais vê os direitos".

Outros participantes também trouxeram para o grupo situações de enfrentamento com a posição de profissionais de saúde como forma de exercer a cidadania.

P4: "O outro médico disse: você fez muito bem em desafiar a enfermeira e não tomar o remédio, a sua sorte foi essa [...] eles não acreditam no que a gente tá falando, o profissional tem que acreditar pra vê o que tá acontecendo [...] por isso acho que as pessoas têm que procurar os seus direitos, também é um direito meu, né?”

P8: "Chegar falar assim, doutora, eu tomei o remédio e não posso toma novamente porque esse remédio é muito forte, da outra vez que eu tomei eu não consegui me mexer, e eu vou trabalhar amanha [...] é meu direito de cidadão chega no meu direito e reclamar".

Percebe-se que os dois últimos participantes trazem suas experiências a partir do exercício da cidadania na saúde como forma de fiscalização de um serviço que não foi devidamente prestado, assim como Pedrosa (1996) relata que a população brasileira ainda não compreende saúde como um direito social e identifica o setor por meio do consumo de serviços. 


\section{Os limites da cidadania}

Nos grupos, os participantes defendiam uma concepção de cidadania voltada para o "ato de solidariedade" em favor de pessoas que necessitam de auxílio, reivindicando direitos junto ao Estado e a execução de deveres para uma sociedade melhor e mais justa. Ao mesmo tempo, eles apontaram uma série de limitações desse exercício, que travam o próprio Estado e suas leis: a repressão sofrida pelas pessoas na busca pelos direitos, a descrença do modelo de democracia representativa e o voto como ferramenta de exercício da cidadania, a ineficiência da publicização dos direitos e o questionamento da igualdade de direitos entre todos os indivíduos da sociedade.

Uma das participantes relata que está respondendo judicialmente por açōes de luta pela moradia na comunidade, mostrando que a busca pelo que seria um direito do indivíduo está sendo barrada pelo Estado, o que a faz desiludir-se:

P8: "A comunidade a gente ajudou a fazer. Fez, né, junto com o povo e eu peço assim que vocês, né, peçam pra mim, que eu me livre dessas coisas da justiça, né, que é difícil ter o nome sujo, né, sempre lutei e nunca fiz o mal pra ninguém”.

Da mesma forma, outro participante complementa:

P2: "Mas sabe o que acontece, a gente vive num sistema de coação muito grande, a pessoa vai lá fala tal coisa já é maltratada, é sempre maltratada, ela desiste”.

Outros apontam o descrédito com a democracia representativa e, como refere Pestana (2007), demonstram uma crise de credibilidade na sociedade brasileira, havendo um descrédito nos políticos, promessas, corrupçōes, desvios de verbas das áreas essenciais e descaso das autoridades, o que leva ao rebaixamento da qualidade de vida da população.

P4: "Na maioria das vezes, ninguém consegue chegar até um político pra reivindicar o que eles prometem, mas a gente continua tentando e acreditando que um dia vai melhorar quem sabe, né? Infelizmente, a gente não tem quase nenhuma esperança pra isso, né?"

P1: “A gente elege essas pessoas aí e fica decepcionado, eu acho que ela falou tá correto e é isso aî".

Também foi levantada a dificuldade da publicização da informação como fato que limita o exercício da cidadania, discussão já trazida por Martins (2008) e Oliveira (2004), como fator necessário para o exercício democrático do controle social e da participação popular, bem como forma de democratizar a informação - ou seja, um compartilhamento do que é público e deve ser utilizado por todos. 
P8: "Não se movimentam porque não sabem de seus direitos. Acho que se eles procu-

rassem se informar mais, eles saberiam quais os deveres deles, né, como cidadãos, de procura a melhor vida pra eles, né, saberem procurar".

Após a colocação de diversos limites e dificuldades da prática de cidadania, dois participantes colocaram seus questionamentos sobre a concepção de cidadania e o pressuposto de igualdade de direitos entre todos os indivíduos.

P1: "Mas será que existe mesmo cidadania? Eu acho que não existe, porque em muitas partes não existe cidadania. Existe cidadania assim pro rico, aquele que tem dinheiro tem cidadania, mas o pobre não tem, não. A gente vê tanta coisa que aparece na televisão, direitos humanos pro fulano de tal, direitos humanos pra quem, só pros ricos? E os pobres? Os pobres não têm direitos humanos, não. $\mathrm{O}$ cara faz e acontece aí, estupra a filha de um cidadão, mata um fulano de tal, aí vem o advogado, passa a mão na cabeça dele, tudo bem, tira ele da cadeia, e o pobre, coitado, se rouba um pãozinho pra cumê, pra matar a fome, vai preso e fica lá cumprindo pena pro resto da vida, $[. .$.$] existe cidadania pra poucos, os pobre é os que mais sofre, viu?”$

A outra participante, corroborando esse questionamento, apontou a desigualdade de direitos nas diferentes classes sociais enfrentadas em várias situações cotidianas:

P8: “isso mesmo, né, a mesma coisa que você tá na fila do banco e você tá de terno e gravata e vem um de chinelo de dedo, né, vai fazer o mesmo processo, mas só que aquele é operário, não é cidadão, aquele que tá ali, né, nem é aceito, até na entrada do banco tá acontecendo isso".

O questionamento da igualdade de direitos entre os cidadão foi colocado por Derrida (2001), que afirma que em virtude do número de excluídos, o conceito tornou-se "suspeito" por ser somente abstrato, não de jure, mas de facto. Já Reis (1988) reconhece que a formalização igualitária assegurada pelo reconhecimento comum dos direitos civis e políticos revelou-se inconsistente, pois existe um padrão de dominação social mostrado por profundas diferenças e desigualdade entre as classes populares, os setores médios e altos da população.

\section{O conceito de participação}

Quando questionados sobre o que seria participação popular, as falam centraramse no movimento coletivo em busca de direitos com reivindicações necessárias para a comunidade. Dessa forma, Teixeira (2009) coloca que seria intervir nas decisões que concernem à vida privada dos indivíduos, em todos os aspectos da vida cotidiana, assim como local de moradia, como preservar a saúde, em que ofício trabalhar etc. 
P4: "Participação popular é trabalhar em prol da comunidade visando o benefício da população, como área de recreação, interando-se de assuntos como a saúde lutando por melhoria do bairro e da cidade em geral".

P1: "Participação popular é quando a gente precisa de coisas como luz e água pra nossa vila e então reunimos os nossos moradores pra poder reivindicar os nossos pedidos, isso é participação popular".

Como última observação dentro deste tema, cabe destacar a ligação realizada pelos participantes entre os temas "cidadania” e "participação popular", em que colocaram o primeiro como sendo uma dimensão teórica que deve ser conhecida por todos e o segundo, o exercício, a efetivação na prática destes conhecimentos.

P4: "Acho que participação é partir pra luta mesmo, e cidadania é ver nossos direitos e deveres cobrar e exigir, pra nós e pra uma população mesmo, participação é chegar e fazer, e cidadania é direitos e deveres de uma comunidade, um complementando o outro".

P6: "Cidadania é viver numa cidade, mas esse viver na cidade não pode ser assim do modo fictício do modo artificial, me lembra logo o termo participação, como é o caso aqui nós, participar de uma reunião”.

\section{Considerações finais}

Por meio deste estudo, constata-se que ainda existe imprecisão no uso do conceito de cidadania entre os segmentos que mais dependem das políticas sociais. Percebem-se, pelos sujeitos da pesquisa, sentidos diferentes empregados ao termo; outros, no entanto, questionam a própria definição e sua existência na nossa sociedade. Essa imprecisão na definição e seus limites de aplicação, como apontado nas falas, podem influenciar negativamente a participação popular nos espaços institucionalizados do controle social do SUS.

Visto que a participação popular na saúde traz a cidadania, desde a Constituição Federativa de 1988, como instrumento para a participação, entende-se que se esta for orientada pela cidadania definida como "ato de solidariedade", "amor ao próximo", busca e execução de direitos junto a um Estado provedor, no qual todos os indivíduos são iguais sob sua tutela e a saúde é um bem de consumo e um direito a ser reclamado, o setor de usuários pode ter muitas dificuldades nos enfrentamentos que venham a ocorrer frente ao Estado dentro dos espaços do controle social. Esses espaços apresentam uma relação desigual entre usuários, trabalhadores em saúde e estado, onde as pressões populares devem ser traduzidas para termos da gestão 
e, da mesma forma, numa sociedade de classes, questóes relacionadas ao poder e ao conhecimento continuam presentes, dificultando a participação dos desiguais.

Outro ponto que merece destaque são os questionamentos sobre os limites do conceito de cidadania, que são representados desde as dificuldades impostas pela legislação, a repressão sofrida pela população no seu exercício da cidadania quando enfrenta o Estado, a descrença na democracia representativa (quando os próprios conselhos gestores utilizam esta forma de espaço democrático), a falta de publicização como dificultadora do exercício da cidadania e até o questionamento sobre a igualdade de direitos entre todos os indivíduos.

Entende-se que a participação popular, assim como definido pelos participantes da pesquisa, deve ser praticada também em outros espaços não-institucionais, assim como refere Bravo (2001), que defende os conselhos locais de saúde. Embora não previstos na forma da Lei Federal no. 8.142/90, estes podem ser traduzidos como possibilidade de ampliação da participação comunitária na fiscalização, proposição e execução da política de saúde. Para a autora, seria uma entidade não instituída jurídica e legalmente, mas que permite a participação da comunidade na elaboração de propostas para a política de saúde em sua localidade. Consiste na articulação dos usuários e dos trabalhadores de saúde, com a finalidade de estabelecer relação entre conselheiros e a base, sendo uma forma de aumentar a mobilização, não afastando os representantes da sua base. Outra forma de participação popular que se torna importante na luta pelas conquistas no campo da saúde fora dos espaços institucionais são, como aponta Pestana (2006), as ações por outras vias, como denúncias na imprensa, passeatas e outras formas de pressão e reivindicação. Constata-se, assim, a necessidade de se encontrar formas alternativas e efetivas de mobilização, no sentido de assegurar os direitos, seja através da contestação e/ou pressão sobre o Estado, firmando-se como efetivo controle público.

Desta forma, a simples participação nos espaços institucionais com esta concepção ainda imprecisa de cidadania pode levar os usuários do SUS a não resolverem suas reivindicações e a apenas cumprirem o papel de aprovadores de programas e pacotes ministeriais de financiamento para a saúde. Este papel pode levar a negociações e acordos com o Estado que, muitas vezes, não condizem com as reais reivindicações que, historicamente construídas, se tornaram bandeiras de luta dos militantes em saúde que acreditam numa saúde pública e de qualidade, conforme explicitada na Constituição Federal de 1988 e nas leis de saúde. 


\section{Referências}

BAKHTIN, M. Marxismo e filosofia da linguagem. 6. ed. São Paulo: Hucitec, 1992.

BOSI, M.L.M.; AFFONSO, K.C. Cidadania, participação popular e saúde: com a palavra, os usuários da Rede Pública de Serviços. Cad. Saúde Pública, Rio de Janeiro, v. 14, n. 2, abr. 1998.

BRASIL. Constituição da República Federativa do Brasil. Brasília: Senado Federal, 1988.

BRASIL. O SUS e o controle social: guia de referência para conselheiros Municipais. Brasília: Ministério da Saúde, 2001.

CARVALHO, A.I. Conselhos de saúde no Brasil: participação cidadã e controle social. Rio de Janeiro: IBAM, 1995.

CHAUÍ, M. Convite a filosofia. 12. ed. São Paulo: Ática, 2002.

DAGNINO, E. ¿La sociedad civil, participación y ciudadanía: que estamos hablando? In: MATO, D. (Coord.). Politicas de ciudadanía y sociedad civil en tiempos de globalización. Caracas: FACES, 2004. p. 95-110.

DAGNINO, E. Sociedad civil, espacios públicos y democratización: Brasil. México: Fondo de Cultura Económica. 2002.

DERRIDA, J. A solidariedade dos seres vivos: entrevista com Evandro Nascimento. Folha de S.Paulo, São Paulo, 27 de maio de 2001, Suplemento Mais!, p. 12-16.

GATTI, B.A. Grupo focal na pesquisa em ciências sociais e humanas. Brasília: Líber Livro, 2005.

MARTINELLI, M.L. Pesquisa qualitativa: um instigante desafio. São Paulo: Veras, 1999.

MARTINS, P.C. et al. Conselhos de Saúde e a Participação Social no Brasil: matizes da utopia. Physis: Revista de Saúde Coletiva, Rio de Janeiro, v.18, n.1, p. 105-122, 2008.

MARX, K.; ENGELS, F. A Ideologia alemã. São Paulo: Martin Claret, 2006.

OLIVEIRA, V.C. Comunicação, Informação e Participação Popular nos Conselhos de Saúde. Saúde e Sociedade, São Paulo, v.13, n.2, p.56-69, maio-ago 2004

PEDROSA, J.I.S. Dilemas e Perspectivas do SUS no Estado do Piauí: uma conversa com conselheiros. Saúde em Debate. Rio de Janeiro, n. 49-50, p.28-32, 1996.

PESTANA, C.L.S. et al. Contradições surgidas no Conselho Gestor da Unidade Básica de Saúde da Família de Vargem Grande, Município de Teresópolis-RJ. Physis: Revista de Saúde Coletiva, Rio de Janeiro, v.17, n.3, p.485-499, 2007.

WANDERLEY-REIS, F. Consolidação democrática e construção do Estado. In:

A democracia no Brasil. Dilemas e perspectivas. São Paulo: Vértice, 1988.

SOUSA, R.M.S. Controle social em saúde e cidadania. Revista Serviço Social \& Sociedade, São Paulo, n.74, p.68-84, 2003. 
TATAGIBA, L. Los consejos gestores y la democratización de las políticas públicas en Brasil. In. DAGNINO, E. (org.). Sociedad civil, espacios públicos y democratización: Brasil. México: Fondo de Cultura Económica, 2002.p. 305-368.

TEIXEIRA, M.L. et al. Participação em saúde: do que estamos falando? Sociologias, Porto Alegre, ano 11, n. 21, 2009.

TEIXEIRA, A.C. et al. La constitución de la sociedad civil en Brasil. IN: DAGNINO, E. (org.). Sociedad Civil, Espacios Públicos y Democratización: Brasil. México: Fondo de Cultura Económica, 2007.

TRIVIÑOS, A. N. S. Introdução à pesquisa em ciências sociais. São Paulo: Atlas, 1987.

VIEIRA, L. Cidadania e globalização . Rio de Janeiro: Record, 2005.

WELMOWICKI, J. Cidadania ou classe? O movimento operário da década de 80 . São Paulo: Instituto José Luis e Rosa Sundermann, 2004. 
Reflections on citizenship and barriers to popular participation in the Unified Health System

This paper presents the contradictions of the concept of citizenship found in research conducted with users of a health unit in the East Zone of Sao Paulo and the resulting barriers to popular participation in the SUS. Data collection was organized into two meetings, discussing the concept of citizenship and popular participation with eight subjects outside the unit's management council. We used the focus group technique. As a result, there was a vagueness of meanings applied to the concept of citizenship. The subjects mentioned a number of limitations to the implementation of this concept, as State's law, the repression suffered by the people, the disbelief in representative democracy and voting as citizenship practices, and the question of equal rights in our society; and popular participation as a form of collective movement in search of solutions to community problems. Therefore, popular participation within the institutional spaces of the SUS with this concept of citizenship can lead users to leaving their demands unsolved by the State in the the management councils. Only with other forms of pressure and noninstitutional mobilization one can have a more effective popular participation and problem-solving view of the concerns of the population and health activists, who struggle for a public health and quality.

> Key words: citizenship; popular participation in health; Unified Health System. 